\title{
Correction to: Evaluation of the real-time TRMM-based multi-satellite precipitation analysis for an operational flood prediction system in Nzoia Basin, Lake Victoria, Africa
}

\author{
Li Li ${ }^{1}$ - Yang Hong ${ }^{1}$ Jiahu Wang ${ }^{1}$ Robert F. Adler ${ }^{2,3}$. \\ Frederick S. Policelli ${ }^{2} \cdot$ Shahid Habib $^{2} \cdot$ Daniel Irwin $^{4} \cdot$ \\ Tesfaye Korme ${ }^{5} \cdot$ Lawrence Okello $^{5}$ \\ Published online: 6 November 2017 \\ (C) Springer Science+Business Media B.V., part of Springer Nature 2017
}

\section{Correction to: Nat Hazards (2009) 50:109-123 https://doi.org/10.1007/s11069-008-9324-5}

Unfortunately, the name of author Daniel Irwin was misspelled as Daniel Irwn in the original publication. We hereby correct this.

The original article can be found online at https://doi.org/10.1007/s11069-008-9324-5.

Yang Hong

yanghong@ou.edu; yanghong@agnes.gsfc.nasa.gov

1 School of Civil Engineering and Environmental Sciences, Center for Natural Hazard and Disaster Center, National Weather Center, University of Oklahoma, 202 W Boyd ET, CEC \#334, Norman, OK 73019, USA

2 NASA Goddard Space Flight Center, Greenbelt, MD 20771, USA

3 Earth System Science Interdisciplinary Center, University of Maryland, College Park, MD 20740, USA

4 NASA Marshall Space Flight Center, Huntsville, AL 35812, USA

5 African Regional Centre for Mapping of Resources for Development (RCMRD), Nairobi, Kenya 